Artigo original

Hegemonia - Revista Eletrônica de Relações Internacionais do Centro

Universitário Unieuro

ISSN: $1809-1261$

UNIEURO, Brasília, número Especial, 2016, pp. 76-90.

Recebido em: $17 / 7 / 2016$

Avaliado em: 7/8/2016

Aprovado em: 23/9/2016

\title{
Desafios Institucionais ao Congresso Nacional Brasileiro: Entre a Estabilidade e a Credibilidade
}

Rodinei Tarciano Silva ${ }^{1}$

Resumo: Este artigo apresenta o Congresso Nacional como resultado de sua evolução institucional, estruturado historicamente e apoiada sobre a estabilidade e a credibilidade institucional. A estabilidade do Parlamento no Brasil depende de uma relação positiva entre a instituição política como órgão político e a cultura política como garantidor de sua estabilidade.

Palavras-chave: Congresso Nacional, Instituições Políticas, Cultura Política

Abstract: This paper presents the Brazilian Congress as the result of its institutional evolution, which is historically structured and based both on stability and credibility. The Brazilian Parliament stability relies on a positive relation between the political institution and the civic culture in order to maintain stability.

Key words: Brazilian Congress, Political institutions, Civic Culture

Os Parlamentos nacionais são hoje uma presença institucional característica em quase todos os países no século XXI. Do ponto de vista histórico podem ser considerados uma invenção antiga, presentes na Grécia e na Roma Antiga, tendo em ambas um período

${ }^{1}$ Doutor em Ciência Política. 
Artigo original

Hegemonia - Revista Eletrônica de Relações Internacionais do Centro Universitário Unieuro

ISSN: $1809-1261$

UNIEURO, Brasília, número Especial, 2016, pp. 76-90.

de apogeu e de declínio. Quanto à Roma Antiga, muito próxima de nós pela linha do tempo e pela herança deixada que foi capaz de resistir aos anárquicos anos da Idade Média europeia, a importância do Senado Romano no contexto da república e do posterior império se fez sobressair até o colapso dos romanos no século $V$.

Na Baixa Idade Média, o Parlamento Inglês emerge juntamente com um maior empoderamento do Estado e de sua jurisdição diante dos feudos. Entretanto o Parlamento Inglês apenas se tornou importante e passou a ter um papel mais próximo dos tempos modernos quando a Revolução Gloriosa depôs e rei absolutista católico James II e conduziu ao trono a sua filha protestante e liberal em uma nova constituição política que dava ao Parlamento maiores poderes como o de fiscalização e de ratificação dos atos reais. Ainda que apenas no século XVIII o Parlamento se tornaria preponderante e ator ativo no sistema político inglês, aquela Revolução pode ser considerada como a instituidora do Parlamento moderno.

Por sua vez, o Congresso dos Estados Unidos inaugurou o Parlamento contemporâneo ainda em 1776, o que inspirou uma nova onda de institucionalismo político que agora daria mais relevância ao papel de um poder legislativo independente e forte, cumprindo um papel de representação popular e carreador dos direitos que poucos anos mais tarde seriam proclamados pela Revolução Francesa.

O Brasil, na época destes acontecimentos ainda uma colônia de exploração portuguesa, se colocava no mundo político de então de forma secundária, corolário do estamento português e dele dependente unicamente. Não havia no Brasil, até 1808, um Estado. Com a elevação da colônia a Reino Unido a Portugal em 1815, o ciclo oficial da Independência do Brasil se inicia sob a linhagem absolutista portuguesa. Com a revolução liberal do Porto e retorno de Dom João 
Artigo original

Hegemonia - Revista Eletrônica de Relações Internacionais do Centro Universitário Unieuro

ISSN: $1809-1261$

UNIEURO, Brasília, número Especial, 2016, pp. 76-90.

VI a Portugal, ficara no Rio de Janeiro um aparato estatal português pronto e já cristalizado nas elites locais que se associara aos reinóis por casamentos, títulos de nobreza, recebimento de terras e participação no funcionalismo público. O monarca português deixara no Brasil do início do século XIX mais do que seu filho Pedro de Bragança. Deixara também uma estrutura política e econômica viável que reunia os interesses elitistas de Belém do Pará até o Rio Grande do Sul, acessível a uma classe social e econômica dominante apta a manejar com sucesso um sistema político independentemente de Lisboa.

Creio que uma importância seminal deve ser creditada a dois acontecimentos que fizeram nascer e se desenvolver a ideia de um constitucionalismo brasileiro em 1821. Em primeiro lugar, a presença de deputados brasileiros eleitos pelas respectivas províncias brasileiras nas Cortes Liberais de 1821 quando da elaboração de uma nova constituição liberal para o Reino Português. Por exigência de Dom João VI, os deputados brasileiros levaram a Lisboa a tese de um constitucionalismo brasileiro, na forma de uma monarquia dual entre Lisboa e Rio de Janeiro. Esta ideia já era corrente na ex-colônia e era nutrida por uma corrente de inclinação liberal liderada por José Bonifácio de Andrada, conselheiro íntimo do príncipe regente do Brasil, futuro Pedro I no Brasil independente. A recusa veemente dos "liberais" portugueses em compartilhar a coroa portuguesa com o Brasil foi não apenas um "tiro no pé" pelas reacionárias cortes que rebaixariam o Brasil à condição anterior a 1808, indo mais além ao precipitar a perda do rico império português americano pelas recalcitrantes cortes "liberais" (pois eram mercantilistas nos atos) deixando às elites brasileiras como alternativa apenas a independência unilateral do aparato político brasileiro, em 
Artigo original

Hegemonia - Revista Eletrônica de Relações Internacionais do Centro Universitário Unieuro

ISSN: $1809-1261$

UNIEURO, Brasília, número Especial, 2016, pp. 76-90.

funcionamento harmônico desde 1815. Um segundo fator que alimentou a idéia de uma assembleia legislativa e constituinte brasileira foi a convocação em 1820 dos "procuradores de províncias", como foram chamados os representantes de províncias que foram à corte brasileira formar um conselho juntamente ao príncipe regente. Estas duas experiências legislativas, ainda que parciais, deram ao movimento constitucionalista nativista maior legitimidade e criou o "esprit de corps" necessário para a declaração da independência em 07 de setembro de 1822, na realidade o ponto final de um processo de emancipação que ocorreu aos poucos desde mais de um ano antes, a la brasileira, em uma ruptura gradual e constante alimentada pela intransigência portuguesa.

A Assembleia Constituinte de 1823 foi instalada em meio à grande euforia nativista, apesar de o medo de que o excesso de liberalismo dos nativistas comprometesse a coesão interna do novo país. Foi uma pena que a polarização da Constituinte de 23 tivesse prejudicado a elaboração de um ponto comum e o radicalismo liberal tenha servido de desculpa para sua dissolução em 1823 e apresentação da carta monárquica de 1824. Oliveira Viana culpa o fracasso da Constituinte ao extremismo entre os liberais exaltados e os conservadores portugueses, que conseguiram colocar D. Pedro I contra os liberais moderados liderados pelos irmãos Andrada, expulsos da Constituinte e exilados. Na realidade, não haveria segundo esse autor possibilidades de aprovação de uma Constituição Nacional neste contexto de grave dualidade e de inexperiência legislativa, levando à outorga da carta de 24, elaborada por um grupo de notáveis, submetida por D. Pedro I a todas as Câmaras Municipais e por todas aprovadas antes da sua entrada em vigor, o que gera 
Artigo original

Hegemonia - Revista Eletrônica de Relações Internacionais do Centro Universitário Unieuro

ISSN: $1809-1261$

UNIEURO, Brasília, número Especial, 2016, pp. 76-90.

dúvidas quanto ao grau de sua imposição, sendo considerada mais liberal que o projeto que tramitava na Constituinte.

Durante o Império, a importância do legislativo no sistema político se deu através da sua forte presença no Gabinete, através do Conselho de Ministros (especialmente após 1847 com a instituição do parlamentarismo e indicação de primeiros-ministros), a rotatividade entre os partidos Conservador e Liberal, o pacto de Conciliação de 1848 entre os dois partidos políticos dando estabilidade ao regime, além de ser a Assembleia Geral um palco de discussões da vida social e política de então.

A origem histórica de um sistema legislativo é de suma importância para analisarmos o seu presente e projetar o seu futuro. Esta "inércia" institucional que é dada pela sua evolução histórica, está presente no funcionamento das instituições através dos tempos. A ruptura do sistema de governo em 1889 não modificou a base institucional do legislativo brasileiro, acomodando no novo Congresso Nacional republicano as elites monárquicas, limitando-se a destituir os deputados (em grande parte por causa da Assembleia Constituinte), deixando os senadores em suas respectivas cadeiras, tirando deles apenas a sua vitaliciedade. Após a revolução de 1930, não houve substituição de elite, mas ampliação do poder legislativo para legitimar no poder político as elites urbanas e industriais. 0 Congresso Nacional da democracia de 1946 se polarizou de tal forma que não havia partidos políticos de centro, sem possibilidades portanto de conciliação, tendo o próprio legislativo solicitado a intervenção militar em 64 tamanha era a paralisia do legislativo, bem à moda de 1823 . Sem contar com o recesso imposto pelos militares em 1969 ao Congresso Nacional, o legislativo brasileiro não ficou paralisado nos anos de chumbo, apesar das pressões dos presidentes 
Artigo original

Hegemonia - Revista Eletrônica de Relações Internacionais do Centro Universitário Unieuro

ISSN: $1809-1261$

UNIEURO, Brasília, número Especial, 2016, pp. 76-90.

militares e de um poder contestatório muito diminuído e até mesmo subterrâneo, preservando intacta uma oposição que emergiria do closet em 1978.

Fora as cassações dos parlamentares empreendidas por Getúlio Vargas (cassação geral) e pelo Regime Militar de 64 (cassações pontuais), o legislativo brasileiro vem em um crescendo que culminou na Nova República. Através desta linearidade histórica é que devemos traçar as nossas perspectivas para o futuro do sistema legislativo, sem o que as conjecturações podem cair no vazio das especulações filosóficas.

As influências externas na vida política interna de um país são inevitáveis, mas não se deve deixar de compreender que, mesmo quando o sistema internacional é a origem, as questões são filtradas nos Parlamentos ao redor do mundo a partir da peculiaridade histórica de cada aparelho político (Santos, 1999). Afirmo que, diante das interveniências externas, o poder legislativo em um país singular faz a sua interpretação e assimilação a partir de sua própria ótica institucional, a qual é condicionada historicamente.

Com o passar dos anos, a tendência é que as instituições ganhem solidez no arranjo institucional do Estado ou passem por mudanças necessárias para se adequar às demandas político-sociais e obtenham um novo equilíbrio. O sistema legislativo encontra unanimidade da comunidade acadêmica quanto à sua estabilidade e solidificação. Como fora demonstrado acima, apesar da ruptura do Estado Novo, que governou sem legislativo, houve um continuum das instituições legislativas brasileiras desde a primeira legislatura imperial. 
Artigo original

Hegemonia - Revista Eletrônica de Relações Internacionais do Centro Universitário Unieuro

ISSN: $1809-1261$

UNIEURO, Brasília, número Especial, 2016, pp. 76-90.

Para a Ciência Política, existe uma independência entre estrutura e cultura institucional, ainda que se relacionem. Uma corrente majoritária trabalha com a hipótese de que a estrutura é o ponto de partida, moldando a cultura através do crescente funcionamento das instituições. Por outro lado, a cultura pode se colocar contra as instituições políticas em regimes considerados "modelo", como nos Estados Unidos e na Europa Ocidental. Nestes países se observa nos últimos anos uma maior oposição e menor apoio aos Parlamentos nacionais. Mais além, está provado que se trata de uma tendência mundial, por estar presente em praticamente todos os países do mundo nos últimos 40 anos, segundo nos mostram os estudos de Ronald Inglehart no painel de pesquisas longitudinais tipo survey desde a década de 70 com uma grande amostra de países, denominado de world values survey, que vem mostrando esta tendência.

A América Latina tem mostrado preocupação por ser uma das regiões do planeta que pior avalia as suas instituições políticas e de forma crescente nos últimos anos. Como hipóteses pode-se apresentar o fato da maior democratização nos últimos anos, o que teria tornado os cidadãos mais críticos dada a possibilidade de se manifestarem mais abertamente sobre uma história recente de ditaduras e falência das políticas econômicas e sociais; o maior acesso da população aos media e uma cultura política cuja crítica permanente às instituições políticas sejam fruto de uma burocracia ainda refratária e depositária de privilégios históricos.

O desafio da credibilidade se torna realmente um problema quando está presente uma questão muito cara aos estudos sobre estabilidade política: a legitimidade. No Brasil, desde 1990, há eleições gerais de grande participação para eleger seus 
Artigo original

Hegemonia - Revista Eletrônica de Relações Internacionais do Centro Universitário Unieuro

ISSN: $1809-1261$

UNIEURO, Brasília, número Especial, 2016, pp. 76-90.

representantes (apesar de o voto ainda ser obrigatório) e repercussão entre todas as camadas sociais que se apresentam no período eleitoral bastante politizadas, cujo resultado das urnas é respeitado sem questionamentos sérios por nenhum setor social ou econômico. A legitimidade das instituições brasileiras parece se confirmar por meios bastante democráticos. Ao largo passa a cultura política da população, que durante o processo político ordinário se posiciona de forma crítica com relação ao sistema. Conforme o estudo de Inglehart e sua equipe na Universidade de Michigan, na América Latina há uma forte correlação entre cultura política e sucesso econômico. Períodos de decadência econômica apresentam um maior apoio a atitudes e a autoridades populistas e menos democráticas.

Não se pode portanto afirmar que o baixo apoio às instituições políticas democráticas signifique, necessariamente, a sua eventual derrocada. Contudo, não há dúvidas que este fator, associado a uma questão de legitimidade destas instituições e de crise econômica, gere um tal mal-estar que resulte em golpes anticonstitucionais.

Sem dúvida existe um grande fosso entre a democracia representativa e a democracia social. Uma coisa são as regras do sistema democrático, presentes em praticamente todos os países do mundo. Outra coisa é o funcionamento harmônico destas instituições de forma a cumprir o seu papel social junto aos seus nacionais.

Em estudo do PNUD (Painel das Nações Unidas para o Desenvolvimento) de 2004 sobre a América Latina, se propõe aos governos da região que vão além de uma mera "democracia de eleitores" e se empenhem em ser "democracias de cidadãos e cidadãs". O estudo mostra que em todos os países as instituições funcionam conforme suas constituições mas falham em melhorar os 
Artigo original

Hegemonia - Revista Eletrônica de Relações Internacionais do Centro Universitário Unieuro

ISSN: $1809-1261$

UNIEURO, Brasília, número Especial, 2016, pp. 76-90.

direitos de cidadania (civis, políticos e sociais) de seus habitantes, tornando portanto ineficaz e inócuo todo o processo político.

Em 1963, Almond \& Verba publicaram um estudo que revolucionaria a Ciência Política e se tornaria um clássico: The Civic Culture. Neste estudo, os autores introduzem a definição de cultura cívica e de cultura política. Cultura Política seriam os conceitos, avaliações, valores e conhecimentos sobre o sistema político. Em sua tipologia existem três tipos ideais: a cultura política paroquial (cidadãos não estão de forma relevante orientados para o sistema político), a cultura política de sujeição (cidadãos se orientam apenas para o sistema político como um todo e para aquilo que é output deste sistema) e a cultura política participante (cidadãos se orientam para o papel de cada indivíduo diante do sistema político, para os inputs e outputs do sistema e para o sistema político como um todo). A cultura cívica, não mais um tipo ideal, seria a proporção da combinação que existe entre estes três tipos ideais em uma determinada sociedade. A ideia dos autores ia além da tipologia. Para eles, haveria uma relação causal determinante entre cultura e instituições, sendo a cultura que moldaria as instituições. Em 1989, após várias críticas e experimentos que contradiziam esta teoria, os autores publicaram o The Civic Culture Revisited, onde admitiram o erro em superestimar o papel da cultura diante das estruturas, revisando a teoria e apresentando uma relação biunívoca: a determinação seria recíproca entre cultura e estrutura política. Apesar de a polêmica teórica ainda continuar na Ciência Política, a corrente majoritária institucionalista hoje já considera a importância dos aspectos culturalistas nas instituições, ainda que os coloque a de forma posterior às instituições: estas sim criam, moldam, vencem ou são vencidas pela cultura política, não o contrário. 
Artigo original

Hegemonia - Revista Eletrônica de Relações Internacionais do Centro Universitário Unieuro

ISSN: $1809-1261$

UNIEURO, Brasília, número Especial, 2016, pp. 76-90.

Em estudo recente na Rodoviária de Brasília (Silva, 2008), foram realizados 1095 questionários em formato survey onde se verificava a cultura política dos passageiros que embarcavam naquele terminal, compostos de assalariados das classes C, D e E, tidos pelos estudos de grandes institutos como o Latinobarómetro como as mais autoritárias. Aquele estudo demonstrou que os questionários padrão não fazem uma distinção importante entre o conceito acadêmico e político de democracia e o que ele realmente significa para os seus entrevistados. Quando perguntados "o que esta palavra, democracia, significa para você?" as respostas se associavam ao campo simbólico dos direitos civis (liberdade, igualdade, fraternidade) do que aos direitos políticos (eleições, instituições democráticas, partidos políticos). Isto significa que é preciso levar em consideração na elaboração e interpretação dos questionários o que os entrevistados entendem por democracia. Na mesma pesquisa, quanto às instituições democráticas, os direitos civis não eram colocados à disposição nem mesmo num cenário populista ou em troca de crescimento econômico, mostrando que os valores democráticos ligados aos direitos civis estavam consolidados nos indivíduos. Entretanto, quando a questão se voltava para as instituições políticas democráticas, a avaliação dos políticos que governam o país eram negativas e até mesmo pejorativas, demonstrando o ressentimento dos entrevistados para com a classe política. Para completar, para mais de $3 / 4$ dos entrevistados a democracia é a melhor forma de governo que existe. A conclusão é que a população das classes mais baixas não seriam autoritárias em relação à democracia e favoráveis à ditaduras populistas, mas sim apresentam severas críticas quanto aos políticos inseridos no sistema, especialmente os parlamentares, considerados os culpados pelas mazelas e contra os quais se deseja o pior: a perda de seus cargos. Esta pesquisa mostra que a cultura 
Artigo original

Hegemonia - Revista Eletrônica de Relações Internacionais do Centro Universitário Unieuro

ISSN: $1809-1261$

UNIEURO, Brasília, número Especial, 2016, pp. 76-90.

política se relaciona à performance dos atores políticos e não à própria estrutura em si. É óbvio que instituições políticas, ainda que de acabamento perfeito, caso não apresentem eficácia, tem riscos de ruir se presentes outros fatores como falta de legitimidade, crise social e econômica.

Está se tornando consenso que uma verdadeira democracia não é aquela onde as instituições seguem as regras do jogo, mas cujo resultado do jogo seja satisfatório para todos os participantes diretos e indiretos. Acredito ser este um dos maiores desafios para o futuro da política no Brasil. Durante a ditadura militar recente houve uma manipulação dos mecanismos democráticos de forma a se gerar uma aparência de democracia eleitoral enquanto os direitos civis e políticos eram flagrantemente violados. Esta experiência exemplifica bem esta questão e mostra que a democratização brasileira somente será efetiva e bem-sucedida quando houver no Brasil uma democracia que vá além da democracia formal e passe a ser uma democracia substantiva, real e com força de se integrar perenemente na cultura política do brasileiro médio.

O processo legislativo brasileiro é tido como lento e ineficiente. $\mathrm{Na}$ realidade, deve-se levar em consideração duas questões relacionadas ao poder executivo: a função informativo e a função legislativa.

O sistema legislativo brasileiro é muito vinculado ao poder executivo. Para formar o seu Gabinete, o Presidente da República forma uma coalizão majoritária no Congresso Nacional a fim de implementar as suas políticas. Com o modelo atual escolhido pelos constituintes de 1988 , o Presidente da República passa a ter um alto poder informativo frente aos deputados por monopolizar os profissionais técnicos e o orçamento, e também uma forte função 
Artigo original

Hegemonia - Revista Eletrônica de Relações Internacionais do Centro Universitário Unieuro

ISSN: $1809-1261$

UNIEURO, Brasília, número Especial, 2016, pp. 76-90.

legislativa relacionada à edição de medidas provisórias com força de lei e possibilidades de interferir na agenda legislativa com elas e com os pedidos de urgências. Desta forma, o processo legislativo, em nome da governabilidade, tende a privilegiar as leis de iniciativa do poder executivo, que apresentam um trâmite mais célere que as leis de elaboração do próprio legislativo.

De forma a competir com o poder executivo, é necessário fortalecer as comissões técnicas e capacitar o legislativo de profissionais capazes de antecipar d avaliar as políticas públicas, apresentando quando possível alternativas bem informadas em relação a estas políticas, resolvendo o problema de falta de informação no legislativo quanto às políticas públicas insuladas no poder executivo (Santos, 2008).

Conclusão

Os Parlamentos enfrentam vários desafios para se consolidar no mundo contemporâneo. Não há, contudo, perigo contra a sua existência que não venha de dentro das próprias fronteiras nacionais. Depois da euforia da globalização afirmar que os Estados-nação estavam fadados a enfraquecerem-se gradualmente, o que se vê nos últimos anos é a sua consolidação e fortalecimento diante crises financeiras globais e dos novos desafios transnacionais como 0 terrorismo, as organizações criminosas e um crescimento nos nacionalismos. Consequentemente, o Parlamento continuará sendo por muito tempo um ator interno importante, por vezes exercendo um papel de ator internacional de relevância. 
Artigo original

Hegemonia - Revista Eletrônica de Relações Internacionais do Centro Universitário Unieuro

ISSN: $1809-1261$

UNIEURO, Brasília, número Especial, 2016, pp. 76-90.

Negar o valor dos Parlamentos nacionais é negar a evolução institucional dos Estados modernos que evoluíram juntamente com suas assembleias representativas. Mais ainda, os parlamentos dão aos governos legitimidade na esfera nacional e internacional. Devem adaptar-se às novas demandas sem contudo se olvidar de traduzir em seu seio, através da perspectiva nacional, estas mudanças, sob o risco de deslegitimá-la por simplesmente acomodar estrangeirismos e mudanças gestadas no ambiente externo sem reflexão ou adaptação às peculiaridades históricas nacionais.

Referências Bibliográficas

ALMOND, Gabriel \& VERBA, Sydney. The Civic Culture. Little, Brown and co.: Boston, 1965.

. The Civic Culture Revisited. Sage: Newburry

Park, 1989.

. The Study of Political Culture. in CROTHERS,

Lane \& LOCKHART, Charles (ed.). Culture and Politics: a reader. St. Martin's Press: New York, 2000.

LATINOBARÓMETRO. Informe Latinobarómetro 2007. Santiago de Chile, 2007.

PNUD. A Democracia na América Latina: Rumo a uma democracia de Cidadãs e Cidadãos. Programa das Nações Unidas para o Desenvolvimento; tradução Mônica Hirts. Santana do Parnaíba, SP: 2004. 
Artigo original

Hegemonia - Revista Eletrônica de Relações Internacionais do Centro Universitário Unieuro

ISSN: $1809-1261$

UNIEURO, Brasília, número Especial, 2016, pp. 76-90.

SANTOS, Fabiano. Como Aperfeiçoar o Sistema Político Brasileiro? In:

VIANA, J. P. \& NASCIMENTO, G. S. O Sistema Político Brasileiro:

Continuidade ou Reforma? Porto Velho: Edufro, 2008.

- Instituições Eleitorais e Desempenho do

Presidencialismo no Brasil. Dados, Vol. 42, 1999.

SILVA, Rodinei. T. A Democracia no Horizonte: Estudo de Cultura Política dos Passageiros que embarcam na Rodoviária de Brasília. Dissertação de Mestrado. Unieuro: Brasília, 2008.

WORLD VALUES SURVEY. Página Eletrônica:

www.worldvaluessurvey.org. 